\title{
PLANEJAMENTO DA PRÁTICA PIANÍSTICA DE CANHOTO DE RADAMÉS GNATTALI: UM ESTUDO DE CASO
}

\author{
Planning a piano practice for Canhoto, by Radamés \\ Gnattali: a case study
}

\author{
ARILTON RodRIGUEs MEDEIROS JÚNIOR \\ Universidade do Estado de Santa Catarina \\ arilton_jr@hotmail.com \\ MARIa Bernardete CASTElan Póvoas \\ Universidade do Estado de Santa Catarina \\ bernardetecastelan@gmail.com
}

\begin{abstract}
Resumo: O planejamento, a organização e a gestão da prática músico-instrumental têm sido foco de investigações artísticas, orientadas por amplos e variados processos. Neste artigo é descrita uma proposta de planejamento da prática pianística, aplicada ao processo de construção da execução da peça Canhoto para piano solo de Radamés Gnattali. A peça foi previamente analisada, seccionada em unidades de trabalho (UTrs) e organizada em planilhas de treinamento (PTr1 e PTr2) segundo o sistema Rodízio, que agrega distribuição e variabilidade da prática (Póvoas, 2017). O processo descrito caracteriza-se como estudo de caso e permitiu adaptar o sistema a uma proposta particular de organização do treinamento, além de levantar aspectos relacionados à potencialização da autorregulação e da prática deliberada, abrindo espaço para adequá-la a propostas experienciais equivalentes.
\end{abstract}

Palavras-chave: Prática pianística. Autorregulação. Sistema Rodízio.

\begin{abstract}
Planning, organizing and managing the musical and instrumental practice have been the focus of artistic investigations, guided by wide and varied processes. This paper describes a proposal for planning the piano practice applied to the construction process for the execution of the piece Canhoto for piano solo, by Radamés Gnattali. The piece was previously analyzed, sectioned in working units (UTrs) and organized in training sheets (PTr1 and PTr2) according to a rotation system, which aggregates distribution and variability of practice (PÓVOAS, 2017). The process described is characterized as a case study and allowed us to adapt the system to a proposal of training organization, besides raising aspects related to the potentializing of selfregulation and deliberate practice, opening space to adapt it to equivalent experimental proposals.
\end{abstract}

Keywords: Piano practice. Self-regulation. Rotation system. 


\section{INTRODUÇÃO}

A necessidade de organização para a prática músico-instrumental tem sido foco de vários segmentos da investigação artística em música. O trabalho de planejamento, organização e gestão da prática de um repertório é tratado na literatura da música por diferentes orientações. Através de análise, escuta de gravações e outros recursos são também utilizados formulários-modelo para controle, monitoramento e avaliação da prática (Klickstein, 2009, p. 8-9).

Em um panorama de investigação sobre desempenho musical, Gabrielsson (2003) fez um levantamento de abordagens sobre planejamento e prática que inclui cerca de 500 artigos desde 1980. A maior parte dos trabalhos discorre sobre "medição do desempenho, mas há um crescente aumento no número de contribuições em modelos de desempenho, planejamento e prática [...]" (Gabrielsson, 2003, p. 221). Barros (2015) investigou "vertentes temáticas dos trabalhos empíricos realizados entre 1980 e 2008 sobre o planejamento da execução instrumental" e justifica a delimitação do período em perspectiva como sendo um período "em que se delimitam e se concentram, em número crescente de publicações, as pesquisas sobre a temática". Mais recentemente, Williamon (2017, p. 209217) apresenta autores como Zimmerman (1990), Paris e Winograd (1990), McPherson e Zimmerman (2002), Jorgensen (2004), Chaffin e Imreh (2001, 2002), Chaffin et al. (2003) e outros que tratam sobre autorregulação, assunto intimamente ligado a planejamento e organização da prática instrumental. Todo esse contexto revela que, no âmbito da investigação artística direcionada à prática instrumental, a pesquisa vem seguindo diferentes e abrangentes tendências.

$\mathrm{Na}$ investigação aqui apresentada, um dos pesquisadores ${ }^{1}$ assume $\mathrm{o}$ papel de sujeito com o propósito de observar critérios de organização e reorganização da prática pianística. É descrito o treinamento para a interpretação da peça para piano solo Canhoto (1943), de Radamés Gnattali ${ }^{2}$ (1906-1988), segundo o sistema de organização e planejamento da prática instrumental denominado Rodizio ${ }^{3}$, com o intuito de relacioná-lo a aspectos contidos na autorregulação. Neste âmbito, o envolvimento empírico pessoal

\footnotetext{
${ }^{1}$ Participou de recitais solo e de câmara, cursos, oficinas e festivais com reconhecidos pianistas e pedagogos, de concursos de piano com premiações, e de seminários de pesquisa. Além de atuar em recitais, desenvolve trabalho como pianista colaborador junto a coros e cantores.

2 Radamés Gnattali: compositor e pianista brasileiro (Porto Alegre, dia 27 de janeiro de 1906 - Rio de Janeiro, 3 de fevereiro de 1988).

${ }^{3}$ O Rodízio é um sistema de estudo instrumental que integra, dentre outros aspectos, planejamento e organização do treinamento, prática distribuída e variabilidade de prática. Idealizado por Maria Bernardete Castelan Póvoas, tal sistema resulta de um processo de experiência pessoal e pedagógico fundamentado na literatura da área da prática instrumental, pianística, coordenação motora e outras. Vem sendo utilizado desde 1993 pela autora, quando, pela primeira vez em meio a outras atividades, preparou o repertório de um concurso em pouco tempo. Sobre o sistema Rodízio encontram-se textos publicados pela autora em 2015 nos Anais do XXV Congresso da ANPPOM, em 2017 na revista OPUS.
} 
pode dispor de significativo valor no contexto de pesquisa no campo da interpretação em música, oportunizando a continuidade da pesquisa acerca do sistema Rodízio.

O processo de construção da execução ${ }^{4}$ pianística aqui apresentado caracteriza-se como um estudo de caso, no qual o caráter subjetivo da experiência de um pesquisador-intérprete que contribui como sujeito (Cano, 2014, p. 133) encontra sua justificativa metodológica. Ao tratar da relação intérprete-compositor, o autor diz que "[...] a experiência particular do investigador com a prática musical constitui um ponto fundamental que desencadeia o processo de investigação artística" (Cano, 2014, p. 133, tradução nossa) ${ }^{5}$. Em adição, o "estudo de caso é caracterizado pelo estudo profundo e exaustivo de um ou de poucos objetos, de maneira a permitir o seu conhecimento [...]" (Gil, 2008, p. 57). Pretende-se, com o desenvolvimento deste trabalho, que seus resultados possam ser aplicados a diferentes situações de investigação em música.

\section{PANORAMA TEÓRICO - PLANEJAMENTO E AUTORREGULAÇÃO}

O planejamento da prática instrumental e a escolha de estratégias apropriadas a serem aplicadas durante o processo de construção de um repertório são essenciais para o êxito do resultado. Aspectos de planejamento, organização e gerenciamento constituintes do Rodízio estão presentes no conceito de autorregulação, aqui relacionado ao "pensar" estratégico. Jørgensen (2004, p. 85) argumenta que as

[...] estratégias de prática podem ser definidas como pensamentos e comportamentos que músicos desempenham durante a prática que permite influenciar seus estados afetivos, motivacionais, ou a maneira como eles selecionam, organizam, integram e praticam novos conhecimentos e habilidades (Jørgensen, 2004, p. 85, tradução nossa) ${ }^{6}$.

Quando o músico faz planos para uma sessão de prática, trata-se do "pensar estratégico", e, quando o músico aumenta o andamento de uma execução, refere-se ao "comportamento estratégico". Nesse contexto, Jørgensen (2004) apresenta três fases relativas ao processo de prática: planejamento e preparação da prática; execução da prática; e observação e evolução da prática, fases também presentes no conceito de autorregulação.

Zimmerman (1990, p. 5, tradução nossa) ensina que "[...] aprendizagem autorregulada refere-se a ações e processos voltados para a aquisição de informações ou habilidades que envolvem ação, propósito e

\footnotetext{
${ }^{4}$ No contexto, execução pianística refere-se às ações de prática e realização interpretativa do texto musical.

5 "En este caso, la experiencia particular del investigador com la práctica musical constituye um punto fundamental que gatilla el proceso de indagación artística” (Cano, 2014, p.133).

6 "[...] practice strategies can be defined as thoughts and behaviors that musicians engage in during practice that are intended to influence their motivational or affective state, or the way in which they select, organize, integrate, and rehearse new knowledge and skills" (Jørgensen, 2004, p.85).
} 
percepções instrumentais pelos aprendizes"7. Já para Santos e Gerling (2010, p. 214), a autorregulação refere-se aos "esforços sistemáticos para direcionar pensamentos, sentimentos e ações na realização de certo objetivo direcionado por metas". No entender de Lehmann (2007, p. 78), significa o músico corresponder às dificuldades das tarefas, solucionando situações técnico-instrumentais e, se necessário, mudar seu comportamento de prática à medida que se torna mais autossuficiente. Essas definições de autorregulação reforçam o argumento de Jørgensen (2004, p. 85) sobre comportamento estratégico já visto aqui.

Segundo Lehmann (2007, p.78, tradução nossa), “a otimização da prática é alcançada principalmente por meio da autorregulação. Isso significa que o indivíduo pode selecionar estratégias apropriadas, planejar, monitorar e avaliar os resultados de maneira cíclica à medida que as dificuldades aparecem"8. Para Barry e Hallam (2002), as habilidades metacognitivas requerem planejamento, monitoramento, avaliação da aprendizagem, autoconhecimento de força e fraqueza pessoal, além de domínio do conhecimento que avalia a natureza das tarefas de modo progressivo guiado por um objetivo. Ou seja, a metacognição engloba a capacidade do indivíduo de compreender o próprio processo de pensamento, tendo o planejamento como ponto de partida para alcançar um resultado. $\mathrm{O}$ monitoramento e a avaliação envolvem aspectos e ações que deverão ser inspecionados e aprimorados no decorrer do processo. Desse modo, em vez de

[...] simplesmente estabelecer o objetivo (inatingivel) de produzir performances perfeitas, os músicos devem empregar estratégias de planejamento, execução e avaliação para identificar e desenvolver suas habilidades de desempenho instrumental (Williamon; Clark; Küssner, 2017, p. 211, tradução nossa) ${ }^{9}$.

Cremaschi (2012) experimentou aplicar formulários de verificação de prática semanal (checklist) para testar o efeito em um grupo de pianistas iniciantes. Os resultados mostraram que os sujeitos do grupo experimental utilizaram mais estratégias metacognitivas de autorregulação em suas práticas, como, por exemplo, planejamento e monitoramento, do que o grupo controle. O autor não identificou as estratégias de autoeficácia ${ }^{10}$ nem de gerenciamento de recursos técnico-interpretativos e concluiu que o

\footnotetext{
7 "Self-regulated learning refer[s] to actions and process directed at acquisition of information or skills that involve agency, purpose, and instrumentally perceptions by learners" (Zimmerman, 1990, p.5).

8 "Optimizing practice is mainly achieved throught self-regulation. This means that a person can select appropriate strategies, plan, monitor the outcome, and revise according to the difficulties encountered" (Lehmann, 2007, p. 78).

9 "Indeed, rather than simply setting the (unattainable) goal of producing note-perfect performances, musicians should employ planning, executive and evaluation strategies to identify and develop their performance skills" (Williamon; Clark; Küssner, 2017, p.211).

${ }^{10} \mathrm{~A}$ autoeficácia não será conteúdo desenvolvido nesse artigo.
} 
checklist pode influenciar a autorregulação da prática pela indução do pianista à autorreflexão. Estratégias dessa natureza poderão conduzir o pianista a uma prática mais deliberada ${ }^{11}$ em função da sistematização por meio do planejamento e da organização de determinado repertório. Também orienta para delimitar metas claras e autocontrole sobre a maior ou menor necessidade de aprimoramento de conteúdo musical específico, de questões técnico-instrumentais e interpretativas, por exemplo. Nesse contexto, o Rodízio também contempla a gestão do treinamento, proporcionando condições para o músico autorregular sua prática.

Segundo Bezerra (2015)12, o pianista utiliza uma estratégia de autorregulação não só na preparação do repertório para a prática, mas também na ação, quando opta por praticar com mãos separadas determinado trecho musical de complexidade técnica. Quando da utilização do sistema Rodízio na prática do repertório pianístico, a autora constatou maior

[...] foco no presente [pois] a ansiedade de ter que tocar a obra toda é neutralizada pelo compromisso de tocar apenas o pequeno trecho selecionado [permitindo] feedback imediato, [pois] ao repetir o trecho com tempo delimitado, o indivíduo pode, a cada vez, avaliar o seu desempenho e utilizar habilidades metacognitivas de automonitoramento e autorregulação, componentes da motivação (Bezerra, 2015, p. 31).

Ademais, pressupõe-se que, durante o intervalo entre uma sessão e outra de treinamento distribuído, seja possível, além da "restauração física e mental" (Garhammer 1991, p. 184), que o músico realize feedback sobre sua prática. Wise, James e Rink (2017, p. 160), citando Jørgensen (2004), orientam que músicos devem alternar a prática instrumental com a prática mental, porquanto a "prática focada sem a ação no instrumento musical dará mais tempo para o ensaio mental e a reflexão, além de evitar o uso excessivo dos músculos" (tradução nossa) ${ }^{13}$. Desse modo, tanto a orientação do treinamento distribuído quanto do ensaio mental auxiliaria o músico a prevenir o trabalho maçante e o desgaste fisiológico, otimizando resultados.

\footnotetext{
${ }^{11}$ Segundo Ericsson (1993, p.369, tradução nossa): “A prática deliberada é uma atividade esforçada que pode ser sustentada apenas por um período de tempo limitado por dia durante períodos prolongados sem levar a exaustão (restrição de esforço)". No original: "To maximize gains from long-term practice, individuals must avoid exhaustion and must limit practice to an amount from which they can completely recover on a daily or weekly basis".

${ }^{12} \mathrm{~A}$ autora trata do Rodízio em uma perspectiva interdisciplinar voltada à Psicologia Transpessoal. Relaciona sua prática pianística ao fenômeno denominado platô/fluxo, definido como um estado de consciência plena e imersão total para uma atividade, sem ser afetado por interferências externas.

13 “[...] Jorgensen $(2004$, p.88) recommends that 'playing practice' should be balanced with 'nonplaying practice' in a single session or over a period of time. [...] Focused, nonplaying practice will give more time for mental rehearsal and reflection and prevent overuse of muscles" (Wise; James; Rink, 2017, p. 160).
} 
Por ser um sistema estruturado de prática, o Rodízio permite ao músico condições para uma aprendizagem autorregulada. Esforços sistemáticos adquiridos no planejamento e na organização da prática poderão direcionar pensamentos e ações antes e durante a realização da prática, tendo em mente um objetivo que pode ser ajustado conforme a necessidade.

\section{O SISTEMA RODÍZIO - CONTEXTO}

O Rodízio visa "a eficiência e a otimização do desempenho, cuja dinâmica ${ }^{14}$ do treinamento é operacionalizada por meio da variabilidade e periodicidade em sessões de prática distribuída de repertório previamente analisado [...]" (Póvoas, 2017, p. 193). Fundamenta-se em argumentos de áreas como prática instrumental, psicologia da música e coordenação motora, entre outras. No Rodízio, o repertório é previamente analisado e distribuído em unidades de trabalho (UTrs) que são delimitadas em função do material técnico-musical e organizadas em planilha de treinamento (PTr). Uma UTr corresponde a uma porção de conteúdo musical ou sessão de treinamento.

Póvoas $(2017$, p. 194) esclarece que os "códigos de marcação dos detalhes observados na(s) partitura(s) podem variar de acordo com opções pessoais de organização". De modo geral, o planejamento é realizado de forma individual e, durante a prática, devem ser estabelecidas metas claras a alcançar com foco na eficiência da execução instrumental.

No Rodízio (Póvoas, 2017), a variabilidade e a distribuição de prática correspondem à alternância de repertório com o intuito de variar o gênero, o estilo e o caráter para evitar a repetição de um mesmo conteúdo, de uma sonoridade e de uma mesma ação motora, pois todo ato repetido por determinado período predispõe o indivíduo a cair no automatismo, fato este que "reduz a vigilância" (Iida, 2005, p.385). Barry e Hallam (2002, p. 152) asseguram que pianistas experts adotam uma variedade de abordagens da prática para manter o alto padrão de execução instrumental, e que, na busca de resultados sonoros desejados, a variabilidade e a distribuição do material de trabalho permitem resultados mais eficazes por meio do acúmulo de horas de prática. Neste contexto, é relevante considerar que o pianista que se faz sujeito neste estudo de caso estava praticando outras obras em paralelo.

Em experimento realizado com um grupo de pianistas, Bangert (2013) identificou que a variabilidade de prática foi benéfica para adquirir habilidades motoras. Segundo Póvoas (2017, p. 191), a variabilidade na ação pianística poderá auxiliar na quebra de monotonia, permitindo resultados proficuos quanto à aquisição, à retenção e à transferência de habilidades

\footnotetext{
14 Nesse contexto, o termo "dinâmica" refere-se ao modo como o instrumentista organiza sua prática instrumental e utiliza variabilidade de ações e/ou tomadas de decisões para evitar o trabalho maçante e otimizar o desempenho.
} 
motoras. Em estudo com 40 universitários sobre o aumento gradual da variabilidade de prática, cuja tarefa foi pressionar teclas numéricas do teclado de um computador em uma sequência $(2,8,6,4)$ com o dedo indicador, Januário et al. (2016, p. 769) mostraram que "os regimes de prática que forneceram menor variabilidade conduziram ao aprendizado de uma estrutura de movimento, enquanto as que forneceram maior variabilidade resultaram na melhora da capacidade de parametrização"15.

No contexto do Rodízio, a distribuição da prática significa dividir o trabalho em sessões ou períodos de treinamento distintos. Magill (2000, p.348) define a prática distribuída como "um esquema [...] em que o período de repouso entre as tentativas ou grupos de tentativas é relativamente grande”. Diversamente da prática distribuída, uma sessão de prática maciça ${ }^{16}$ poderá levar o músico à repetição desatenta de padrões musicais e sofrer cansaço físico e/ou mental, baixando seu rendimento no trabalho. Essa informação é confirmada quando Iida (2005, p. 385) enfatiza que a “[...] monotonia do trabalho repetitivo reduz a vigilância e tende a provocar erros”. Assim, a prática distribuída por meio das pausas para descanso entre sessões permite reparo e restauração físiológica ao músico (Garhammer, 1991, p. 184), possibilitando melhores condições físicas e mentais para o desenvolvimento técnico-instrumental.

Além da distribuição do treinamento, o sistema Rodízio encontra respaldo em argumentos da Ergonomia que o justificam na perspectiva da organização sistematizada da prática com foco na precisão da ação, enfatizando que, "[...] quanto mais alto é o nivel de precisão a ser atingido, menores devem ser as sessões de treinamento" (Kroemer; Grandjean, 2005, p. 118). Os autores acrescentam que a prática deve ser desempenhada em sessões curtas de treinamento, visto que um indivíduo fatigado está mais propenso a manifestar vícios técnicos motores que tornam o trabalho mais difícil para retificar a ação. É comum na prática instrumental músicos habituarem-se à prática maciça, situação em que a fadiga pode tornar-se imperceptivel. Corroborando esse argumento, Magill (2000, p. 259) informa que resultados de experimentos mostraram que a prática de habilidades com sessões mais curtas melhora a aprendizagem.

\section{MÉTODO E RESULTADOS - ORGANIZAÇÃO PARA A PRÁTICA PIANÍSTICA DO “CANHOTO"}

De acordo com a proposta do sistema Rodízio, a organização para o treinamento da peça Canhoto foi planejada em três etapas: escolha da peça;

\footnotetext{
15 O termo "Parametrização" é aqui utilizado referindo-se à capacidade de definição e decisão por ações relacionadas à habilidade motora.

${ }^{16}$ A prática maciça consiste no tipo de prática onde períodos para descanso físico são relativamente curtos ou inexistentes, o que a torna mais contínua (Magill, 2000, p. 348).
} 
organização do Rodizio com análise e organização da planilha de treinamento; e prática.

\section{Etapa 1: Escolha da peça - Critérios}

Entre os fatores que contribuíram para a escolha da peça Canhoto, de Radamés Gnattali, além da opção por uma obra de compositor brasileiro, foram: o caráter, o material técnico-pianístico e os aspectos motivacionais intrínsecos de estrutura rítmica, harmônica, melódica. A peça é relativamente curta (57 compassos) e permite ao pianista deparar-se com situações técnicas de média complexidade distribuídas entre elementos musicais peculiares de identidade nacional.

Em Canhoto, na linha melódica escrita para ser tocada na região grave do piano executada pela mão esquerda, compassos 7 ao 16, o trabalho contrapontístico e características harmônicas, bem como os saltos entre acordes para as duas mãos, compassos 20 ao 23, também foram aspectos técnico-musicais que contribuíram para a escolha da peça. Santos (2002, p.11) expõe que os elementos com maiores graus de incidência na peça são, entre outros: apojaturas e bordaduras, valorização melódica do contratempo, baixo melódico e sincopa. Segundo o autor,

A influência do jazz está presente nos dois choros de Radamés Gnattali através da sonoridade das tensões e alterações incorporadas aos acordes, bem como em algumas progressões típicas daquele gênero. Diferentemente do choro tradicional, os acordes utilizados no jazz aparecem em sua maioria na posição fundamental, para que as tensões existentes soem como tal (Santos, 2002, p. 11).

Quanto aos aspectos musicais e técnico-pianísticos, destacam-se as linhas melódicas, as articulações e os saltos, como, por exemplo: as linhas melódicas no baixo, em geral para a execução da mão esquerda, como aquelas destacadas na Figura 1 a serem executadas em legato, a segunda delas finalizando em staccato. 


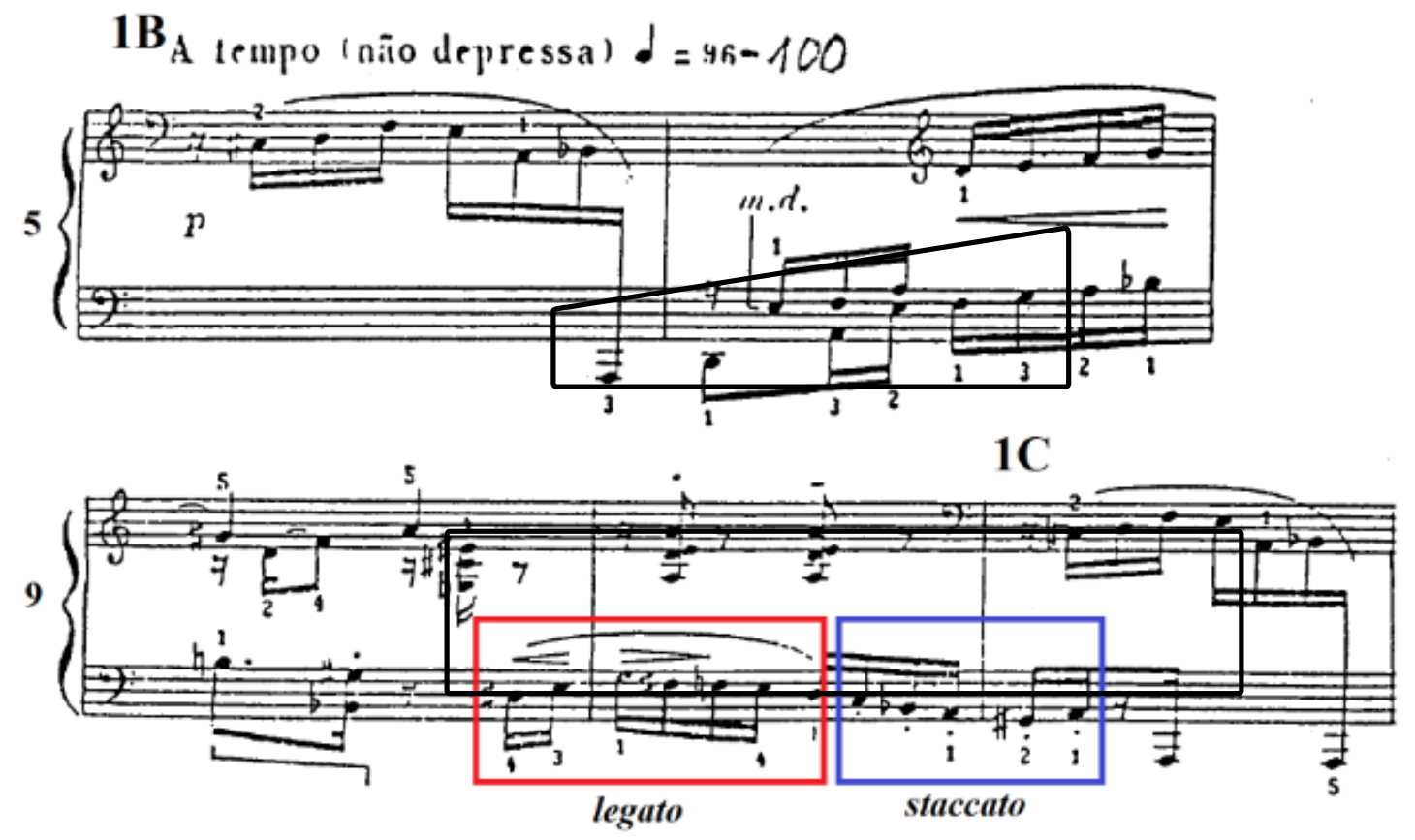

Figura 1: Linha melódica da mão esquerda. Fonte: Gnattali (1958, c. 5,6 e 9-11; autores).

Quanto aos saltos entre eventos musicais,

[...] em tal contexto, incluem-se situações técnico-musicais em que, além de exigirem a realização de movimentos assimétricos entre os segmentos direito e esquerdo (braços, mãos e dedos), os eventos musicais distantes entre si demandam médios e longos deslocamentos (Póvoas, 1999, p. 750).

A figura seguinte mostra duas situações técnico-musicais entre eventos equivalentes, em destaque na Figura 2, para cuja realização pianística exige o deslocamento dos segmentos (braços e mãos) da esquerda para a direita do teclado, em curto espaço de tempo.

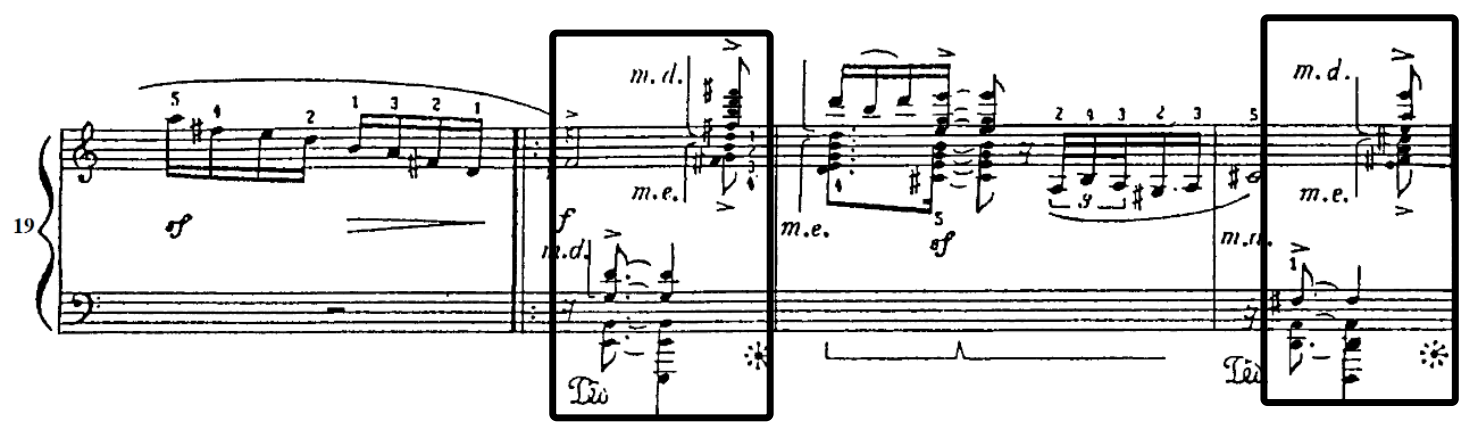

Figura 2: Distância entre eventos musicais. Fonte: Gnattali (1958, c. 1922; autores). 
Para a realização de uma interpretação condizente com o caráter e o estilo, nesta e em situações técnico-musicais semelhantes às supracitadas, o pianista deve desenvolver habilidades motoras específicas de deslocamento e controle do peso/ataque (densidade sonora), em função do que o texto musical requer (sinais de expressão, articulação e dinâmica).

Quanto à motivação para a escolha da peça Canhoto, chamaram-nos a atenção, entre outras características, a rítmica, a sonoridade e a alusão ao jazz. Amiúde, para que haja engajamento na construção de uma execução, é necessário que o conteúdo técnico-musical em foco apresente certo grau de desafio, cuja tensão é compensada com a satisfação em tocar a peça, gerando equilíbrio psicoemocional.

\section{Etapa 2: Organização do Rodízio}

a) Análise da peça

Esta etapa de organização do Rodízio teve início na primeira semana de contato com a peça Canhoto, começando com a identificação da forma e seguindo com cadências, intenções fraseológicas, dinâmicas e pontos específicos que exigiam maior capacidade técnica, como, por exemplo, distância entre eventos e contracantos. Póvoas (2017, p.194) esclarece que deve ser realizada a

[...] análise das estruturas (macro e micro), densidade (camadas), identificação de repetições idênticas e semelhantes, [reconhecimento] de padrões (ritmicos, melódicos), audição, entre outros detalhes. [...] As partes ou segmentos idênticos devem ser marcados colocando-se sinal de repetição sobre eles e um traço ou dois para delimitar o final do trecho repetido e início de outro. São anotados detalhes não coincidentes entre os trechos equivalentes, mesmo que caracterizem uma pequena diferença, por vezes circulando-os. Detalhes musicais como uma ou duas nota(s), acorde, harmonia (encadeamento), sinais de expressão, entre outros, podem indicar pontos de elisão e direcionamentos interpretativos, entre outros aspectos de interesse. Padrões recorrentes também são destacados e marcados os pontos de elisão entre partes, entre outros detalhes.

A peça foi dividida em partes ou seções integrais ${ }^{17}(1,2,3$ e 4), seccionadas em subseções nominadas com números e letras: $1 \mathrm{~A}, 1 \mathrm{~B}, 1 \mathrm{C}, 2 \mathrm{~A}$, 2B etc. A subdivisão e uma análise de subseções foram estabelecidas como critério de planejamento, ações não diretamente implícitas na explicação sobre a organização do Rodízio, pois o sistema foi criado com o objetivo de otimizar a prática de repertório pianístico constituído de mais de uma peça (Póvoas, 2017, p.193), aqui aplicado à prática de uma única peça. Na Figura 3 são mostrados os compassos 1 ao 18 da peça Canhoto, onde as seções

\footnotetext{
${ }^{17} \mathrm{O}$ termo "seção integral" refere-se a uma UTr sem subdivisão de letra (1A, 1B...), por exemplo, UTr 1, 2, 3, 4.
} 
integrais (UTrs maiores) encontram-se entre colchetes no sentido vertical, e as subseções (UTrs menores) estão delimitadas por colchetes no sentido horizontal.

Dedithune e pedal de

FRAICISCO MGSONE

\section{CANHOTO}

\section{chôno}
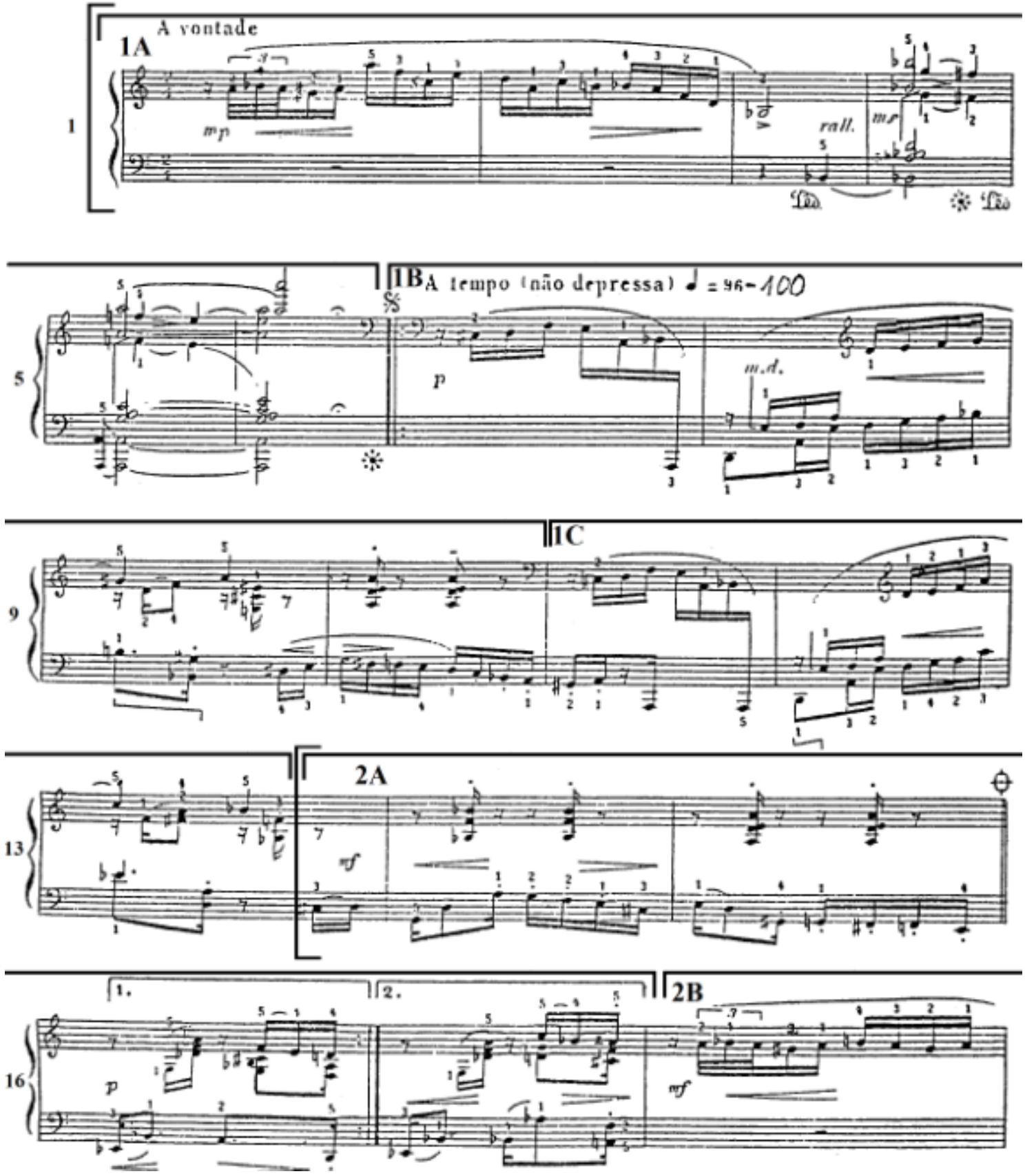

Figura 3: Organização de UTrs na peça Canhoto de Radamés Gnattali. Fonte: Gnattali (1958, p. 1, c. 1-18; autores). 
b) Organização das planilhas de treinamento

Para gestão da prática e como parte do monitoramento, durante a prática de Canhoto foram utilizadas duas planilhas de treinamento: PTr1 e PTr2 (Cremaschi, 2012; Klickstein, 2009; Barry; Hallam, 2002). A PTr1 se constitui das subseções ou UTrs menores (1A, 1B, 1C, 2A, 2B, 2C, 3A, 3B, 3C, 4A e 4B), enquanto a PTr2 contempla UTrs integrais (1, 2, 3 e 4). A primeira planilha de treinamento (PTr1) foi elaborada como teste com o objetivo de auxiliar na determinação do tempo de treinamento de cada seção e do período de experimentação, intercalando a prática entre os trechos mais e menos complexos. Esse teste forneceria mais subsídios para identificar e relatar o modo como foram aplicadas as estratégias de organização e de ações executadas na prática. Convém lembrar que uma UTr corresponde a uma porção de conteúdo musical ou sessão de treinamento; nesta PTr1 cada UTr foi ainda seccionada em 3 subseções cada uma, exceto a UTr 4, dividida em apenas duas partes. A prática dessa planilha teve a duração de um mês. A ordem das UTrs foi colocada de forma aleatória na PTr1, variando entre mais complexas e menos complexas. Conforme exemplificado na Tabela 1, a ordem do treinamento das UTrs ocorre de cima para baixo.

\begin{tabular}{c|l|c}
\hline \multicolumn{3}{c}{ Planilha de Treinamento 1 (PTr 1) } \\
\hline UTrs & Marcas condensadas & Alternância de complexidade \\
\hline 4B & $\square \square$ & Complexo \\
\hline 2B & $\square \square$ & Menos Complexo \\
\hline 1A & $\square \square$ & Complexo \\
\hline 3B & $\square$ & Menos Complexo \\
\hline 2A & $\square$ & Complexo \\
\hline 1B & $\square$ & Menos Complexo \\
\hline 4A & $\square$ & Complexo \\
\hline 2C & $\square$ & Menos Complexo \\
\hline 3C & $\square$ & Complexo \\
\hline 3A & $\square$ & Conos Complexo \\
\hline 1C & $\square$ & \\
\hline
\end{tabular}

Tabela 1: Planilha de Treinamento I (PTr I). Fonte: Elaborada pelo autor (2018).

$\mathrm{Na}$ PTr1 as subseções foram colocadas em ordem aleatória na organização do Rodízio para os seguintes fins: 1) a realização do treinamento de cada uma das subseções de maneira concentrada, desconsiderando, 
temporariamente, as seções em sequência. Pressupõe-se que o estudo concentrado em uma única seção sem a obrigação de tocar a seção subsequente, pelo menos na fase de sedimentação do conteúdo técnicomusical, deve permitir maior foco na seção em treinamento; 2) foram colocadas por ordem de complexidade, alternando seção mais complexa com menos complexa. A intenção dessa alternância foi tornar o trabalho mais atraente, possibilitando que frases musicais simples fossem executadas em menos tempo.

Após a prática da PTr1, com a prática de seções suficientemente curtas e com a peça já memorizada, foi elaborada uma segunda planilha (PTr 2) para o treinamento de seções mais longas ou integrais. Essa planilha teve como critério de delimitação de cada UTr uma frase musical ou duas, sem aquelas subdivisões (1A, 1B, 1C...), e uma das UTrs de estudo foi designada prioridade. Significa que no Rodízio há

[...] possibilidade de determinar uma unidade como "prioridade" durante um período de três a cinco dias, escolhida por seleção e a critério do pianista, para ser colocada no topo da lista e ser praticada ao início de cada sessão de treinamento do Rodízio, a cada dia ou em mais sessões, quando houver. Desta forma, unidades mais complexas podem ser treinadas mais vezes. (Póvoas, 2017, p. 196).

Esse recurso abre espaço para intensificar o trabalho de situações técnico-musicais mais complexas, com conteúdos de escrita musical mais densa, por exemplo, oportunizando a autorregulação da prática. Essa planilha foi ordenada de acordo com o sentido de continuidade e com o fluxo da peça, como, por exemplo: UTr 1, 2, 3, 4.

\section{Etapa 3: Prática da peça Canhoto}

$\mathrm{Na}$ segunda semana foi iniciado o treinamento da peça ao piano, e a definição do dedilhado, utilizando-se a PTr1, ficando estabelecido que a prática de cada sessão de treinamento teria 20 minutos de duração e frequência de duas vezes ao dia. Logo ao início desse período decidiu-se que, devido ao volume de material musical estipulado para cada UTr, poder-se-ia reduzir o tempo para duas vezes de 10 minutos por dia de segunda a quinta e três sessões na sexta-feira, iniciando-se um novo ciclo de prática utilizando as "marcações condensadas"18, o que permitiria ter contato com a peça inteira. O treinamento foi realizado com a prática de mãos separadas e mãos juntas para averiguar questões técnico-interpretativas e movimentos adequados.

\footnotetext{
18 Póvoas (2017, p. 197) define as marcações de seções estudadas como "esquema de marcação condensado". Marcações condensadas referem-se aos traços colocados ao lado de cada UTr praticada como uma forma de controlar e gerenciar a prática na Planilha de Treinamento (PTr).
} 
$\mathrm{Na}$ terceira semana, a prática foi intensificada com foco na memorização do texto musical. O trabalho instrumental foi realizado com o intuito de testar a memória antes de terminar o tempo estabelecido para cada sessão de prática: dois minutos em média. Nesse período foram utilizadas ações como a prática de mãos juntas e prática de mãos separadas, além de prática em andamento lento, antecipação dos movimentos, antecipação do gesto para a seção seguinte e teste de dedilhado no andamento sugerido na partitura.

$\mathrm{Na}$ quarta semana de treinamento, foram praticados os encadeamentos entre as UTrs e com as diferenças entre os materiais musicais entre as casas 1 e 2 (Figura 4).

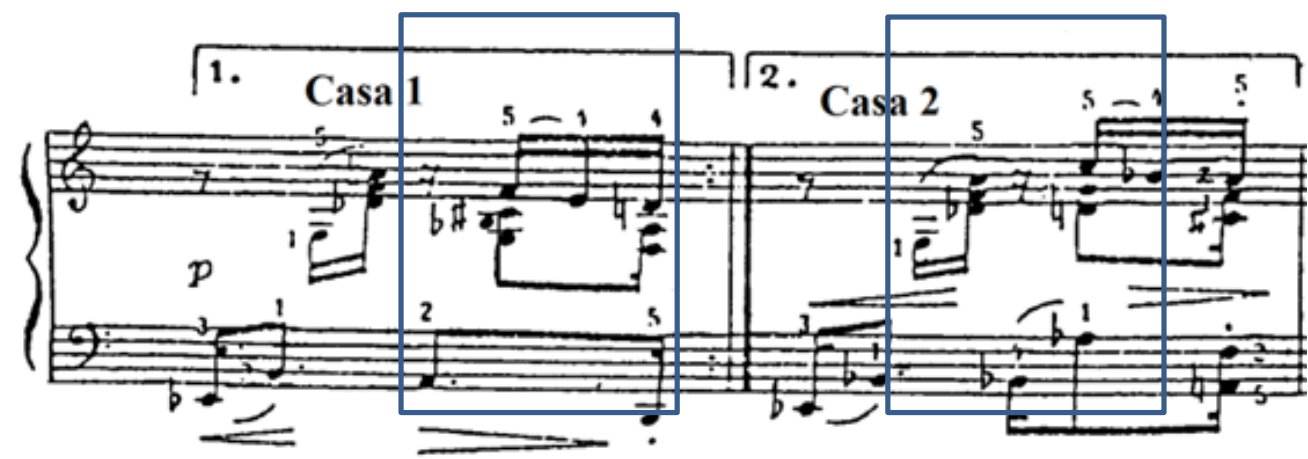

Figura 4: Diferenças entre os materiais. Canhoto, de Radamés Gnattali. Fonte: Gnattali (1958, p. 1, c. 16 e 17).

Ainda nessa semana de treinamento, percebeu-se que algumas seções foram mais bem assimiladas e memorizadas do que outras (UTRs 1A, 2B, 3A, 4B), fato que mais tarde indicaria a necessidade de reorganizar as UTrs em nova planilha (PTr2).

Com a execução pianística de Canhoto em andamento próximo ao requerido na partitura, na quinta semana observou-se a necessidade de atenção constante sobre a prática para que detalhes interpretativos não fossem omitidos. Nessa fase, houve maior dominio técnico-musical na execução integral da obra, situação que permitiu identificar trechos musicais para os quais seria necessário aprimorar mais o trabalho técnicopianístico por meio da hierarquização de UTrs, com a aplicação do recurso "prioridade" inserido na PTr2, conforme Tabela 2 já apresentada aqui. A construção da PTr2 foi uma forma de gerir a prática usando o recurso prioridade (autorregulação). 


\begin{tabular}{l|c}
\hline \multicolumn{2}{c}{ Planilha de Treinamento 2 (PTr2) } \\
\hline UTrs & $\begin{array}{l}\text { Marcas } \\
\text { condensadas }\end{array}$ \\
\hline Prioridade: 4 & $\square$ \\
\hline 1 & $\square$ \\
\hline 2 & $\square$ \\
\hline 3 & $\square$ \\
\hline 4 & $\square$ \\
\hline
\end{tabular}

Tabela 2: Planilha de Treinamento 2 (PTr2). Fonte: Elaborado pelos autores (2018).

\section{DISCUSSÃO E RESULTADOS}

Trabalhos que utilizam modelos de checklist para gerenciar a prática instrumental, como os de Klickstein (2009) e Cremaschi (2012), dentre outros, respaldam a organização e a distribuição sistematizada de unidades de trabalho em planilhas de treinamento, assim como esta particular proposta de aplicação do sistema Rodízio. Quanto à organização das UTrs na PTr1, a prática com sessões curtas permitiu melhor retenção e transferência de habilidades motoras em situações técnico-pianísticas, como nas distâncias entre eventos musicais (Figura 2), e linha melódica da mão esquerda (Figura 1). Esse fato corrobora o argumento de Magill (2000, p.259), de que a prática de seções curtas melhora a aprendizagem.

A forma de organizar, integrar e utilizar estratégias na ação instrumental cria capacidades e possibilidades que permitem ao músico administrar a sua própria prática, de forma independente. A autorregulação manifesta-se tanto nas decisões de planejamento quanto em mudanças de comportamento durante o treinamento (Lehmann, 2007, p.78). No presente estudo a autorregulação foi representada tanto pelos critérios de organização da prática em planilhas de treinamento quanto pela decisão de aplicar o recurso "prioridade" na PTr2 para aprimorar o trabalho técnicopianístico em trechos musicais pontuais.

Os critérios de organização podem ser realizados de modo individual (Póvoas, 2017, p.194) por meio de anotações pessoais na partitura. Assim, as adaptações de organização e reorganização da prática pianística nos moldes do Rodízio foram determinadas por: alternâncias entre UTrs complexas e menos complexas; delimitação do tempo de prática (10 minutos, 2 vezes por dia); prática de UTrs subdivididas (PTr1) para a fase inicial de treinamento da peça; e prática de UTrs integrais (PTr2) para a fase final de treinamento da peça. Lembrando que a autorregulação refere-se a "esforços sistemáticos para direcionar pensamentos, sentimentos e ações na realização de certo objetivo direcionado por metas" (Santos; Gerling, 2010, p.214). Tais adaptações e critérios de organização da prática pianística vão 
ao encontro do conceito de autorregulação tratado neste artigo. Quanto à alternância entre UTrs complexas e não complexas, entra a questão da variabilidade de prática de Barry e Hallam (2002, p.152).

Pode-se ver, na Figura 5, um resumo esquemático da associação entre características do sistema: distribuição da prática, variabilidade de prática, frequência de prática e o recurso de hierarquização da prática denominado "prioridade", fundamentos integrantes do Rodizio, com adaptação para a prática de única peça, Canhoto. Convém lembrar que a variabilidade e a frequência de prática derivam da distribuição.

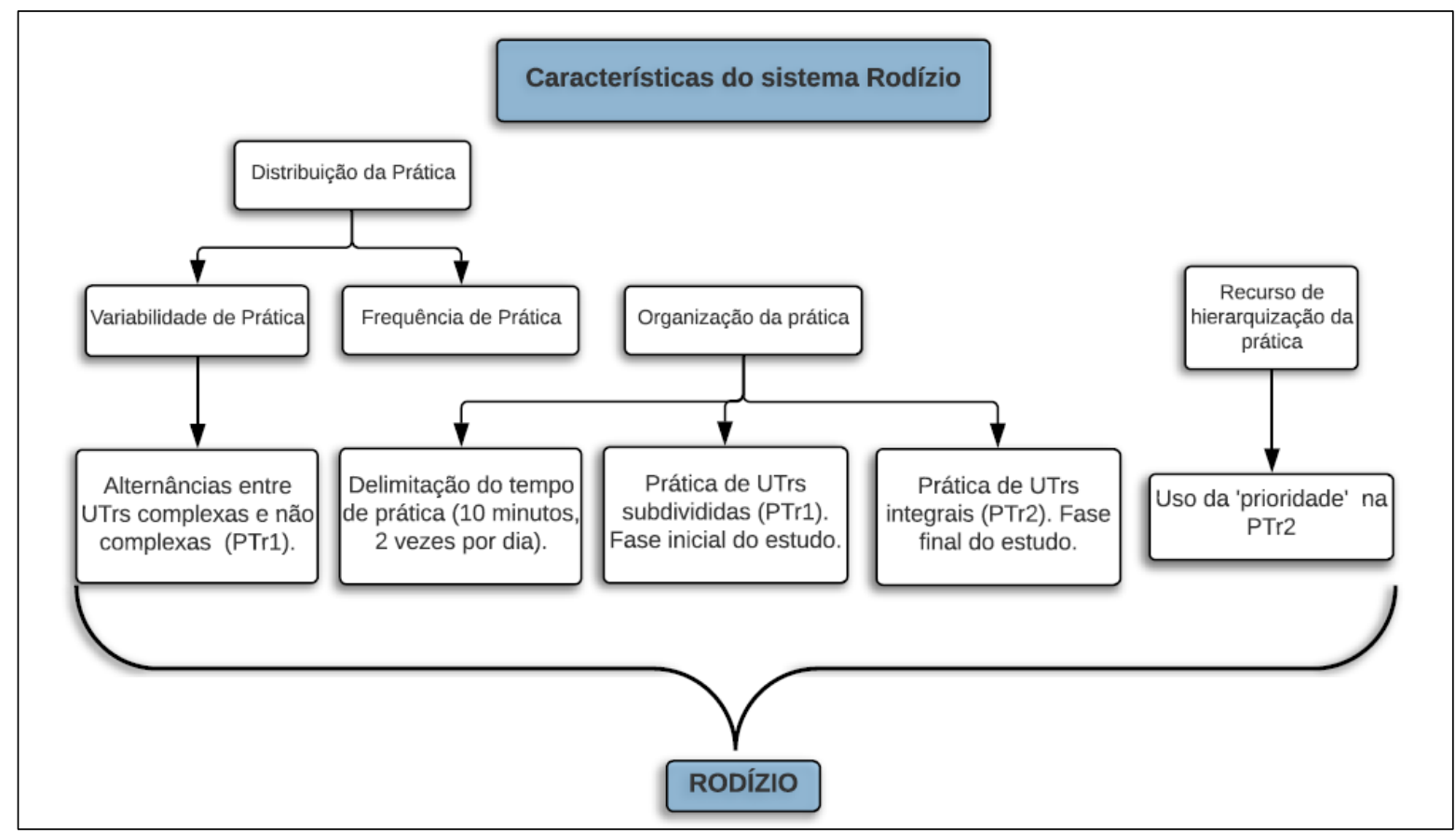

Figura 5: Características do sistema Rodízio - Adaptação à organização da prática pianística da peça Canhoto. Fonte: Elaborado pelos autores (2018).

A frequência é uma característica que provém de toda a sistematização organizada na planilha de treinamento e da gestão da prática intrínseca nas marcações condensadas (Tabelas 1 e 2).

O processo de organização e prática da execução pianística da peça Canhoto permitiu, como se vê no esquema da Figura 5, alcançar significativo nível de: compreensão analítica da determinação de UTRs, metas claras (definição da UTr prioridade, por exemplo), motivação (frequência e persistência no trabalho ao piano), autocontrole sobre o estado de evolução de UTrs ou monitoramento controlado da prática (gerenciamento no treinamento das UTrs), retenção e transferência de habilidades motoras. Como consequência, tais aspectos inerentes às ações durante o processo aqui em discussão conduziram o sujeito a potencializar uma prática 
autorregulada e deliberada, devido, por exemplo, à utilização do diário de bordo (controle). Parte desse conteúdo encontra-se na Figura 6.

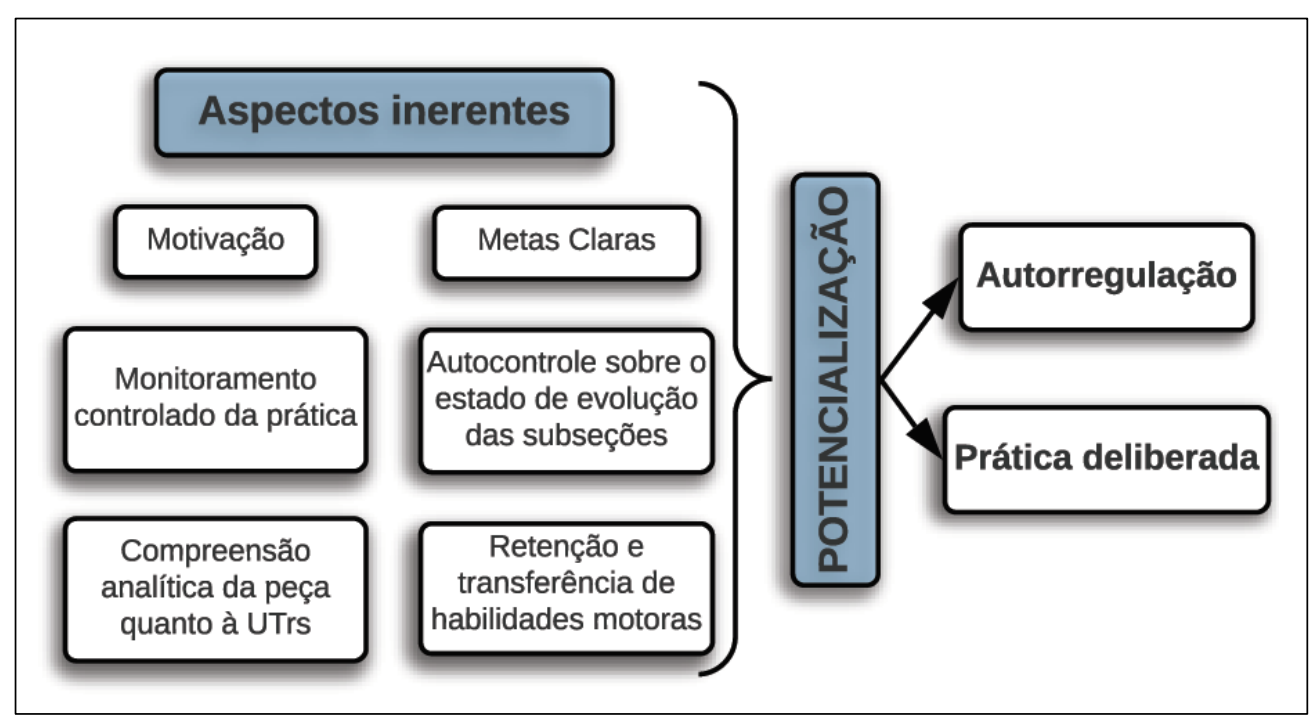

Figura 5: Sistema Rodízio e prática da peça Canhoto: aspectos inerentes observados. Fonte: Elaborado pelos autores (2018)

Durante o processo de construção da execução pianística da peça Canhoto, a autorregulação pôde ser potencializada pela constância no monitoramento operacionalizado através da observação constante e do registro de aspectos técnico-pianísticos, tanto aqueles já musicalmente resolvidos como os que necessitavam de aprimoramento, dentre os quais citam-se, por exemplo, distância entre eventos musicais (Figura 2) e delineamento sonoro de linha melódica da mão esquerda (Figura 1). Já a prática deliberada foi potencializada pelo envolvimento cognitivo que a autorregulação proporcionou no tocante à sistematização, organização e gerenciamento da prática. Desse modo, as marcações condensadas na PTr1 e na PTr2, bem como a utilização do recurso "prioridade", foram fatores que influenciaram positivamente a autorregulação do treinamento pianístico.

\section{CONSIDERAÇÕES FINAIS}

De modo experiencial, para construir a execução pianística da peça Canhoto, foi delineada uma proposta particular de organização e planejamento da prática ajustada aos moldes do sistema Rodizio. Ao final do processo descrito, na sexta semana, os pesquisadores, o pianista e o observador perceberam a potencialização de aspectos inerentes à autorregulação e à prática deliberada. A motivação foi um fator consequente, viabilizando a otimização da prática e possivel aumento de eficiência no resultado de uma execução instrumental com maior controle no desempenho técnico-interpretativo da peça em estudo. 
A partir de estudo de caso único, guiado por fundamentos da coordenação motora, como distribuição e variabilidade da prática, integrando planejamento e organização, o sistema permitiu ao pianistasujeito desenvolver metas claras e autocontrole monitorando o estado de evolução de UTrs, da motivação. Além disso, como resultado de toda a sistematização implícita no controle das marcações condensadas, o uso da UTr "prioridade" oportunizou uma prática pianística devidamente autorregulada no que diz respeito às mudanças de comportamento do treinamento, por vezes necessárias para o autodomínio equilibrado de uma execução pianística.

Outros estudos deverão ser realizados com o objetivo de melhor avaliar o sistema em questão. Esta proposta e adaptações, mais as correlações levantadas, poderão servir na orientação de protocolo experimental para ser aplicado a sujeitos pianistas em investigação artística de cunho qualitativo e/ou quantitativo.

\section{REFERENCIAS}

BARRY, Nancy; HALLAM, Susan. Practice. In: PARNCUTT, Richard; MCPHERSON, Gary. The science \& psychology of music performance: creative strategies for teaching and learning. Oxford: Oxford University Press, 2002. p. 151-165.

BARROS, Luís Cláudio. Retrospectiva histórica e temáticas investigadas nas pesquisas empíricas sobre o processo de preparação da performance musical. Per Musi, [s.1.], n. 31, p. 284-299, jun. 2015. FapUNIFESP (SciELO). Disponivel em: http://dx.doi.org/10.1590/permusi2015a3115.

BANGERT, Marc; WIEDEMANN, Anna; JABUSCH, Hans-christian. When of the same is more: benefits of variability of practice in pianists. International Symposium On Performance Science, Vienna, Austria, p. 117-122, jan. 2013.

BEZERRA, Denise. Ação Pianística e Estados de Consciência: uma abordagem integrativa transpessoal. 2015. 84 f. Dissertação (Mestrado em Música) - Universidade do Estado de Santa Catarina, Florianópolis, 2015.

CANO, Rubén-López; OPAZO, Úrsula S. C. Investigación artística en música: problemas, métodos, experiencias y modelos. Barcelona, 2014. Disponivel em: <http://rlopezcano.blogspot.com.br/2014/09/investigacion-artisticaen-usica.html>. Acesso em: 10 jul. 2017.

CHAFFIN, R.; IMREH, G. A comparison of practice and self-report as sources of information about the goals of expert practice. Psychology of Music, v. 29, p. 39-69, 2001.

CHAFFIN, R. et al. Seeing the big picture: piano practice as expert problem solving. Music Perception, v. 20, n. 4, p. 465-490, 2003. 
CREMASCHI, Alejandro M. The effect of a practice checklist on practice strategies, practice self-regulation and achievement of collegiate music majors enrolled in a beginning class piano course. Sempre: Research Studies in Music Education, Colorado Boulder, USA, v. 1, n. 1, p. 223-233, 2012.

GABRIELSSON, Alf. Music performance research at the millennium. Psychology Of Music, Sweden, v. 31, n. 3, p. 221-271, 2003.

GARHAMMER, John. Principios de Treinamento e Desenvolvimento. In: RASCH, Philip J. Cinesiologia e Anatomia Aplicada. 7. ed. Rio de Janeiro: Guanabara Koogan, 1991.

GIL, Antonio Carlos. Métodos e Técnicas de Pesquisa Social. 6. ed. São Paulo: Editora Atlas, 2008.

GNATTALI, Radamés. Canhôto. Partitura. Rio de Janeiro: Editora Musical Brasileira, 1958.

IIDA, Itiro. Ergonomia: projeto e produção. 2. ed. São Paulo: Edgard Blücher, 2005.

JANUÁRIO, Marcelo Silva et al. Aumento gradual da variabilidade de prática: efeito na aprendizagem da estrutura e na parametrização da habilidade. Revista Brasileira de Ed. Fís. e Esporte, São Paulo, p. 769-779, set. 2016.

JØRGENSEN, Harald. Strategies for Individual Practice. In: WILLIAMON, Aaron. Musical excellence: strategies and techniques to enhance performance. Oxford: Oxford University Press, 2004. p. 85-103.

KLICKSTEIN, Gerald. The Musician's Way: a guide to practice, performance, and wellness. Oxford: Oxford University Press, 2009.

KROEMER, K. H. E.; GRANDJEAN, E. Manual de Ergonomia: adaptando o trabalho ao homem. 5. ed. Porto Alegre: Bookmann, 2005.

LEHMANN, Andreas C.; SLOBODA, John A.; WOODY, Robert H. Psychology for Musicians: understanding and acquiring the skills. Oxford: Oxford University Press, 2007.

MAGILL, Richard A. Aprendizagem Motora: conceitos e aplicações. 5. ed. São Paulo: Edgard Blücher, 2000.

MCPHERSON, G.; ZIMMERMAN, B. J. Self-regulation of musical learning: a social cognitive perspective. In: COLWEL, R.; RICHARDSON, C. (Org.). The new Handbook of Research on Music Teaching and Learning. Oxford: Orxford University Press, 2002. p. 327-347.

PARIS, S. G.; WINOGRAD, P. How metacognition can promote academic learning and instruction. In: JONES, B. J.; IDOL, L. (Orgs.). Dimensions of 
Thinking and Cognitive Instruction. Hillsdale, NJ: Lawrence Erlbaum, 1990. p. $15-51$.

PÓVOAS, Maria Bernardete Castelan. Controle do movimento com base em princípio de relação e regulação do impulso-movimento. Possiveis reflexos na ação pianística. Tese (Doutorado em Música - Práticas Interpretativas) Instituto de Artes, Universidade Federal do Rio Grande do Sul, Porto Alegre, 1999.

PÓVOAS, Maria Bernardete Castelan. Desempenho pianístico e organização do estudo através do Rodizio: um sistema de treinamento baseado na distribuição e variabilidade da prática. Opus, [s.1.], v. 23, n. 1, p.187-204, 30 abr. 2017. OPUS. http://dx.doi.org/10.20504/opus2017a2308.

SANTOS, Regina; GERLING, Cristina. Investigação e autorregulação na preparação de uma obra pianística. In: Simpósio de Cognição e Artes Musicais, 6., 2010, Rio de Janeiro. Anais... Rio de Janeiro: Maurício Dottori, 2010. p. 214-220.

SANTOS, Rafael dos. Análise e considerações sobre a execução dos choros para piano solo Canhoto e Manhosamente de Radamés Gnattali. Per Musi. Belo Horizonte, v. 3, p. 5-16, 2002.

ZIMMERMAN, Barry J. Self-Regulated Learning and Academic Achievement: An Overview. Educational Psychologist, New York, v. 1, n. 25, p. 3-17, 1990.

WILLIAMON, Aaron; CLARK, Terry; Küssner Mats. Learning in the spotlight: aproaches to self-regulating and profiling performance. In: Musicians in the making: Pathways to Creative Performance. New York: Oxford University, 2017. $1 \mathrm{v}$.

WISE, Karen; JAMES, Mirjam; RINK, John. Performers in the practice room. In: Musicians in the making: Pathways to Creative Performance. New York: Oxford University, 2017. $1 \mathrm{v}$.

YIN, Robert K. Estudo de Caso: planejamento e métodos. 2. ed. Porto Alegre: Bookman, 2001. 
Arílton Rodrigues Medeiros Junior é Mestre em Música (Interpretação e Criação Musical) como bolsista da CAPES e graduado no curso de Bacharelado em Piano em (2015) pela Universidade do Estado de Santa Catarina. Como bolsista de iniciação científica (CNPq e PROBIC) integrou os grupos de pesquisa: Processos Músico-instrumentais; Música, Cultura e Sociedade (2012-2017), com participação e publicação em eventos científicos. Como pianista participa ativamente de recitais solo e de câmara, cursos, oficinas e festivais, e de concursos de piano com premiações.

Maria Bernardete Castelan Póvoas é professora associada na Universidade do Estado de Santa Catarina (UDESC) atuando nos cursos de Bacharelado e Pós-graduação na mesma instituição. É bacharel, mestre e doutora pela Universidade Federal do Rio Grande do Sul (UFRGS). Desenvolve pesquisa interdisciplinar sobre desempenho pianístico e música de câmara, com publicações nas revistas Em Pauta, Revista Eletrônica de Musicologia, DaPesquisa, Opus e Vórtex. Realiza recitais solo e de câmara em diferentes formações, estreias e gravação de CD. Encontra-se como pesquisadora visitante na Universidade de Aveiro, Portugal, integrada no INET-md (2018-2019). 